\title{
USE OF PAPER SPRAY-MASS SPECTROMETRY TO DETERMINE THE CHEMICAL PROFILE OF RIPE BANANA PEEL FLOUR AND EVALUATION OF ITS PHYSICOCHEMICAL AND ANTIOXIDANT PROPERTIES
}

\author{
Viviane D. M. Silva ${ }^{a}$, Priscila B. F. Arquelaua, Mauro R. Silva ${ }^{a}$, Rodinei Augustib, Júlio O. F. Melo ${ }^{\mathrm{c}, *}, \odot$ and Camila A. Fante ${ }^{\mathrm{a}}$ \\ ${ }^{a}$ Departamento de Alimentos, Faculdade de Farmácia, Universidade Federal de Minas Gerais, 31270-901 Belo Horizonte - MG, Brasil \\ bDepartamento de Química, Universidade Federal de Minas Gerais, 31270-901 Belo Horizonte - MG, Brasil \\ 'Departamento de Ciências Exatas e Biológicas, Universidade Federal de São João Del-Rei, 35701-970 Sete Lagoas - MG, Brasil
}

Recebido em 15/11/2019; aceito em 04/02/2020; publicado na web em 14/04/2020

\begin{abstract}
In this work, the peels of ripe banana (Musa sp.), variety "Prata", were used to prepare a flour, which was evaluated for its physicochemical characteristics and antioxidant activity. The characterization of its chemical profile was performed by a fast and simple method: paper spray-mass spectrometry. This flour had high carbohydrate content and total dietary fiber, and significant amount of total phenolic compounds with antioxidant activity. In addition, this flour exhibited higher water-holding, oil-holding and swelling capacities than those of fruit by-products reported in the literature. Fourier-transform infrared spectroscopy confirmed the presence of functional groups of cellulose, hemicellulose, and lignin, constituents of insoluble dietary fiber. By the paper spray-mass spectrometry technique, it was possible to suggest the presence of 26 substances such as organic acids, phenolic acids, flavonoids, sugars, quinones, and terpenoids. Thus, this study demonstrated that the ripe banana peel flour has potential application as an ingredient for functional foods.
\end{abstract}

Keywords: agricultural waste; bioactive compounds; fingerprints; ionization; technological properties.

\section{INTRODUCTION}

Banana is one of the oldest and most important crops in the world, and Brazil is one of the main producers. The global production of bananas in 2017 was of 114 million tons. ${ }^{1}$ In 2019, the Brazilian production reached 7.1 million tons. ${ }^{2}$ However, this activity generates large volumes of waste that often have no commercial value and no application, being a serious problem for producers or processing industries, but they are an excellent source of high-added value compounds. $^{3}$

There is a growing interest in a better use of fruit and vegetable by-products, due to their ease of obtaining and low cost, aiming at sustainability, generation of added-value products and reduction of environmental impact. ${ }^{3}$

Banana peels represent about $35 \%$ of the fruit weight. ${ }^{4}$ Generally, they are discarded and may cause serious environmental problems, but are also used as feed or organic fertilizer. ${ }^{5}$ However, banana peels contain nutrients, often in higher proportion than in the pulp, such as high levels of dietary fiber, especially the insoluble fraction, starch in the early stages of ripening, protein, and phenolic compounds..$^{5,6}$ These constituents increase stability and conservation of the nutritional value and color of the food, and inhibit microbial growth, so it is interesting to consider them as alternative sources of food or as ingredients in the preparation of food and pharmaceutical products. ${ }^{7}$

Banana peel is composed also of carotenoids, flavonoids, biogenic amines, sterols, terpenes, and enzymes.$^{5,8-10}$ Due to their antioxidant and antimicrobial properties, the peels have been used in the treatment of several diseases. However, they also have potential to be used as flour for food processing. ${ }^{7,9}$

The characterization of the constituents of a food can be made by various techniques such as high-performance liquid chromatography, high-performance liquid chromatography mass spectrometry and gas chromatography-mass spectrometry. However, these are timeconsuming methods that require a laborious preparation of the sample.

*e-mail: onesiomelo@gmail.com
Paper spray-mass spectrometry (PS-MS) is an ultrafast ionization technique, which obtains fingerprints in broad bands of mass and in which sample preparation is minimal or unnecessary. ${ }^{11-14}$

Therefore, the aim of this study was to characterize the flour of "Prata" banana peel in ripening stage 7 as to its proximate composition, physicochemical parameters, total phenolic compounds content, antioxidant activity, and chemical profile using PS-MS.

\section{EXPERIMENTAL}

\section{Material}

The raw material consisted of ripe banana peels of the variety "Prata" (Musa sapientum AAB) in ripening stage 7 (yellow with brown spots, according to the color scale of Von Loesecke) collected in Belo Horizonte, Minas Gerais, Brazil, from October 2016 to April 2017. To reduce the enzymatic browning, the peels were immersed in $0.5 \%$ (w/v) citric acid solution for $30 \mathrm{~min}$, ground, frozen, drained, and dehydrated in a ventilated oven (FANEM, 320-SE, Brazil) at $60{ }^{\circ} \mathrm{C}$ for $24 \mathrm{~h}$. The dried peels were ground to pass through a $32 \mathrm{mesh}$. The samples obtained were stored in freezer in glass containers and, after obtaining all the flour necessary for the study, all batches were mixed in order to obtain a single sample of ripe banana peel flour. The produced flour had a dry basis yield of $5.6 \%$.

Folin-Ciocalteu's reagent, 2,2'-azinobis-3-ethyl-benzothiazoline6-sulfonic acid (ABTS), 2,4,6-tris(2-pyridyl)-S-triazine (TPTZ), 2,2-diphenyl-1-picrylhydrazyl (DPPH), 6-hydroxy-2,5,7,8-tetramethylchromane-2-carboxylic acid (Trolox), and $\alpha$-amylase were purchased from Sigma-Aldrich. The pancreatin and pepsin were purchased from Merck. All other chemicals and solvents were of analytical grade.

\section{Characterization of banana peel flour}

The color of the banana peel flour was evaluated in a spectrophotometer (Konica Minolta, CM-2300d, Tokyo, Japan) 
equipped with CIELab scale. The color parameters were L* (lightness), $\mathrm{a}^{*}$ (red to green) and $\mathrm{b}^{*}$ (yellow to blue). The coordinates $\mathrm{a}^{*}$ and $b^{*}$ were used to calculate $h^{\circ}$ (hue angle), corresponding to the color itself, and $\mathrm{C}^{*}$ or chroma (color intensity). ${ }^{15}$ The evaluation was performed in triplicate.

The $\mathrm{pH}$ and total soluble solids (TSS) were assessed in a flour suspension ( $8 \% \mathrm{w} / \mathrm{v})$, in triplicate. ${ }^{16}$ After $5 \mathrm{~min}$ of stirring and $30 \mathrm{~min}$ of standing, the sample was filtered and subjected to readings using a pH meter (Bante Instruments, 920, China) and a refractometer (Hanna Instruments, HI 96801, USA), respectively. The technological properties, such as water-holding capacity (WHC), oil-holding capacity (OHC), and swelling capacity (SC) were determined according to Wang et al. ${ }^{17}$

Protein, lipids, ashes, ${ }^{18}$ moisture, carbohydrate, ${ }^{19}$ starch, ${ }^{20}$ and soluble and insoluble dietary fiber ${ }^{18,21}$ were determined, in triplicate, in the banana peel flour. The results were expressed in $\mathrm{g} 100^{-1} \mathrm{~g}$ of the banana peel flour (on a dry basis).

Fourier-transform infrared spectroscopy (FTIR) analysis was performed in spectrometer (Shimadzu IRAffinity - 1), with DLaTGS (deuterated and L-alanine-doped triglycine sulfate) detector and attenuated total reflectance (ATR) accessory with zinc selenide crystal. The banana peel flour spectrum was obtained over the range of $4000-500 \mathrm{~cm}^{-1}$ with 20 scans per experiment at a resolution of $4 \mathrm{~cm}^{-1}$.

\section{Preparation of extracts of banana peel flour}

Extraction was done according to the procedure described by Rufino et al..$^{22}$ to determine the content of phenolic compounds, to evaluate the antioxidant activity and analyze the chemical profile. The banana peel flour $(2.5 \mathrm{~g})$ was mixed with $10 \mathrm{~mL}$ of methanol/ water $(50: 50, \mathrm{v} / \mathrm{v})$. After $1 \mathrm{~h}$ at room temperature, the samples were centrifuged at $3493 \times g$ for 22 min (Excelsa II, FANEM, 206BL, Brazil) and the supernatant was retrieved. Afterward, $10 \mathrm{~mL}$ of acetone/water $(70: 30, \mathrm{v} / \mathrm{v})$ were added to the residue, and a new incubation and centrifuging were repeated at the same conditions described above. Both supernatants were mixed, and distilled water was added until $25 \mathrm{~mL}$ was reached.

\section{Total phenolic compounds and antioxidant activity}

The total phenolic compounds of banana peel flour were determined by using the Folin-Ciocalteau method. ${ }^{23}$ The result was expressed as gallic acid equivalents ( $\mathrm{mg} \mathrm{GAE} \mathrm{g}^{-1}$ sample). The antioxidant activity was evaluated by DPPH, ${ }^{18}$ FRAP, and ABTS. ${ }^{22}$ The analysis was performed in triplicate and in a low-light environment.

\section{PS-MS fingerprints}

The chemical profile analysis of the banana peel flour was done according to the procedure described by Silva et al., ${ }^{13}$ using the mass spectrometer LCQ Fleet (Thermo Scientific, San Jose, USA), equipped with a paper spray ionization source. The extract was filtered through a $0.22 \mu \mathrm{m}$ nylon syringe filter, and $2.0 \mu \mathrm{L}$ were applied on the edge of the chromatographic paper cut in an equilateral triangle shape $(1.5 \mathrm{~cm})$. Methanol $(40.0 \mu \mathrm{L})$ was transferred to the chromatographic paper, and the voltage source was connected for data acquisition. The sample was analyzed, in triplicate, in positive and negative ionization modes.

For the analyses, the instrument was operated with PS-MS source voltage equal to $+5.0 \mathrm{kV}$ (positive ionization mode) and $-3.5 \mathrm{kV}$ (negative ionization mode); capillary voltage of $40 \mathrm{~V}$; transfer tube temperature of $275^{\circ} \mathrm{C}$; tube lens voltage of $115 \mathrm{~V}$; and mass range from
100 to $1000 \mathrm{~m} / \mathrm{z}$. The ions and their fragments obtained in this analysis were identified based on the data described in the literature. Collision energies used to fragmentize the compounds varied from 15 to $40 \mathrm{~V}$. The mass spectra obtained were processed with Xcalibur software.

\section{Statistical analysis}

Results were expressed with means and their respective standard deviations. Pearson's correlation coefficients were determined using SPSS 15.0 for Windows software.

\section{RESULTS AND DISCUSSION}

\section{Characterization of ripe banana peel flour}

The physicochemical properties and the proximate composition results are shown in Table 1 . The ripe banana peel flour exhibited brown color. Similar color was found in peel flours from bananas of different stages of ripeness and variety in the studies of Alkarkhi et al. ${ }^{16}$ and Castelo-Branco et al. ${ }^{24}$

Table 1. Physicochemical properties and proximate composition (dry matter basis, except moisture) of ripe "Prata" banana peel flour

\begin{tabular}{cccc}
\hline \multicolumn{2}{c}{ Physicochemical properties } & \multicolumn{2}{c}{ Composition $\left(\mathrm{g} \mathrm{100} \mathrm{g}^{-1}\right)$} \\
\hline Lightness & $40.83 \pm 0.61$ & Moisture & $6.48 \pm 0.10$ \\
$\mathrm{~h}^{\circ}$ & $62.00 \pm 0.12$ & Ash & $7.47 \pm 0.06$ \\
Chroma & $27.15 \pm 0.29$ & Protein & $8.56 \pm 0.00$ \\
$\mathrm{pH}$ & $4.70 \pm 0.02$ & Lipids & $14.42 \pm 0.37$ \\
TSS $\left({ }^{\circ}\right.$ Brix $)$ & $3.10 \pm 0.00$ & Carbohydrates & $21.43 \pm 0.39$ \\
WHC $\left(\mathrm{g} \mathrm{water} \mathrm{g}^{-1}\right)$ & $6.01 \pm 0.27$ & Starch & $0.93 \pm 0.03$ \\
OHC $\left(\mathrm{g} \mathrm{oil} \mathrm{g}^{-1}\right)$ & $3.79 \pm 0.13$ & SDF & $3.22 \pm 0.10$ \\
SC $\left(\mathrm{mL} \mathrm{g}^{-1}\right)$ & $5.07 \pm 0.16$ & IDF & $44.95 \pm 0.96$ \\
\hline
\end{tabular}

Mean value \pm standard deviation, $\mathrm{n}=3$. TSS: total soluble solids; WHC: water-holding capacity; OHC: oil-holding capacity; SC: swelling capacity; SDF: soluble dietary fiber; IDF: insoluble dietary fiber.

The part of the fruit, ripening stage ${ }^{16}$ pretreatment application prior to drying, and drying conditions and methods ${ }^{25}$ can influence the physicochemical properties of flour. The banana pulp flour is generally lighter than that obtained from the peel, as demonstrated by Alkarkhi et al., ${ }^{16}$ which may be due to phenols oxidation, degradation of pigments, caramelization and Maillard reaction during the drying process of the peels. ${ }^{25}$

The ripe "Prata" banana peel flour is acidic. Its $\mathrm{pH}$ and TSS content were lower than those of the ripe Cavendish banana peel flour (pH 5.47 and $3.46^{\circ}$ Brix). ${ }^{16}$ The TSS in banana peels corresponds to the presence of glucose, fructose, and sucrose, and the higher the stage of ripening, the higher this value. ${ }^{26}$

The WHC is the capacity of a material to retain water in its matrix and is related to the amount of protein and dietary fiber, mainly hemicellulose and pectin, and the physical condition of starch in the flour. ${ }^{16,27,28}$ In this study, the WHC was similar to the values found by Alkarkhi et al. ${ }^{16}$ and Torres-Oblitas et al. ${ }^{27}$ in ripe banana peel flours (6.1-8.2 $\mathrm{g} \mathrm{g}^{-1}$ and $5.4 \mathrm{~g} \mathrm{~g}^{-1}$, respectively), but was greater than those found in unripe plantain peel flour $\left(3.5 \mathrm{~g} \mathrm{~g}^{-1}\right),{ }^{29}$ pequi peel flour (3.7-4.0 $\left.\mathrm{g} \mathrm{g}^{-1}\right),{ }^{15}$ buriti peel flour $\left(1.1 \mathrm{~g} \mathrm{~g}^{-1}\right),{ }^{30}$ and wheat flour $\left(1.9 \mathrm{~g} \mathrm{~g}^{-1}\right) \cdot{ }^{31}$ Porosity, different particle size, preparation process, and various fiber structures can cause these variations. ${ }^{28}$

The $\mathrm{OHC}$ refers to the ability of a food to retain fat during its processing, preserving the flavor and improving texture..$^{27,30} \mathrm{The} \mathrm{OHC}$ 
value of ripe "Prata" banana peel flour was comparable with that of unripe plantain peel flour $\left(2.2-4.1 \mathrm{~g} \mathrm{~g}^{-1}\right)^{29}$ and higher than those reported in ripe Cavendish banana peel flour by Alkarkhi et al. ${ }^{16}$ $\left(0.93-1.28 \mathrm{~g} \mathrm{~g}^{-1}\right)$ and by Torres-Oblitas et al. ${ }^{27}\left(0.9 \mathrm{~g} \mathrm{~g}^{-1}\right)$, and in wheat flour $\left(1.1 \mathrm{~g} \mathrm{~g}^{-1}\right) .{ }^{31}$ Size and hydrophobic nature of the fiber particles, fiber composition, several surface properties, and total charge density can cause these differences in this property. ${ }^{28}$

The SC is related to porosity, crystallinity, and characteristics of the fibrous matrix components. ${ }^{17}$ The ripe banana peel flour had a SC value similar to those of the soluble dietary fiber of orange peel (4.8 and $\left.6.3 \mathrm{~mL} \mathrm{~g}^{-1}\right)^{17}$ and of papaya peel ( 4.1 and $\left.4.5 \mathrm{~mL} \mathrm{~g}^{-1}\right),{ }^{32}$ indicating that it can be used as an ingredient in products for weight control, because it can increase the sensation of fullness. ${ }^{32}$ Therefore, the ripe banana peel flour had better technological properties than other types of flour and can be used in the preparation of bakery products to improve the texture, with claim of functional food. ${ }^{27}$

Regarding the chemical composition, it is observed in Table 1 that the banana peel flour is rich in insoluble dietary fiber, representing over $93 \%$ of total dietary fiber, containing high content of carbohydrates and significant amounts of proteins and lipids. Starch content is very low, due to the high stage of ripening. The moisture content is within the values recommended for flour by the Brazilian legislation, which must be less than $15 \% .^{33}$

Emaga et al. ${ }^{6}$ observed that, in general, the variety does not affect the centesimal composition of peels, unlike the ripening stage. These authors analyzed six varieties of banana peels in three stages of ripening, dehydrated at $60{ }^{\circ} \mathrm{C}$ for $24 \mathrm{~h}$, and found that the more mature peels, i.e., in more advanced stages of ripening, showed higher levels of the constituents.

Angelis-Pereira et al..$^{34}$ analyzed unripe banana peels (ripening stage 3), variety "Prata", dehydrated at $60{ }^{\circ} \mathrm{C}$ for $36 \mathrm{~h}$, and obtained similar results of protein $(8.12 \%)$ and soluble dietary fiber $(3.53 \%)$, while the contents of moisture, lipids and insoluble dietary fiber were lower, and those of ashes and carbohydrates were higher than the levels found in this study. In unripe bananas, starch is one of the main digestible carbohydrates but, during ripening, the starch content decreases while the soluble sugar increases, which occurs due to the action of enzymes that degrade starch and participate in the formation of sugars. ${ }^{26}$ According to these results, it was verified that the ripening stage of the fruit influenced the composition of the flour, due to the variations found in this study and those obtained by Angelis-Pereira et al. ${ }^{34}$ corroborating with the observation made by Emaga et al. ${ }^{6}$

Fruit peels have a higher fiber content than the pulp, which is due to their protective function against external threats. ${ }^{30}$ The highlight of the ripe banana peel flour obtained was its high content of dietary fiber, with the insoluble portion at highest concentration. Health organizations recommend an intake of 25 to $38 \mathrm{~g} \mathrm{day}^{-1}$ of dietary fiber for body functionality in adults, ${ }^{35}$ so the use of this flour is a good alternative as an ingredient in many products.

The FTIR spectrum was obtained to verify the functional groups present in the ripe banana peel flour (Figure 1) and was similar to the spectrum reported by Pelissari et al..$^{36}$ and Oliveira et al. ${ }^{37}$

A low-intensity broad band at $3230 \mathrm{~cm}^{-1}$ corresponds to the stretching of the -OH groups. ${ }^{38}$ The band at $2916 \mathrm{~cm}^{-1}$ was described as $\mathrm{C}-\mathrm{H}$ stretching vibrations in cellulose and hemicellulose, ${ }^{36,37}$ and the band at $2860 \mathrm{~cm}^{-1}$ can be due to methoxyl groups ${ }^{37}$ The next peak, at $1707 \mathrm{~cm}^{-1}$, can indicate ester linkage of the $p$-coumaric acid of lignin or vibrations of acetyl and uronic ester groups of hemicelluloses. ${ }^{36}$ According to Oliveira et al., ${ }^{37}$ the band at $1600 \mathrm{~cm}^{-1}$ represents the superposition of $\mathrm{C}=\mathrm{O}$ stretching vibration of pectin with $\mathrm{C}=\mathrm{C}$ aromatic chain stretching of lignin. The aromatic ring vibrations of lignin can be observed at $1520 \mathrm{~cm}^{-1} \cdot{ }^{36}$ In the region between 1480 and $1390 \mathrm{~cm}^{-1}$, the peaks are related to the bending modes of $-\mathrm{CH}_{3}{ }^{26}$ while the peaks observed in the range of $1390-1270 \mathrm{~cm}^{-1}$ correspond to $\mathrm{CH}_{2}$ bending, indicating the presence of cellulose in the flour. ${ }^{37}$ The peak at $1234 \mathrm{~cm}^{-1}$ indicate $\mathrm{C}-\mathrm{O}$ stretching of lignin and the one at $1060 \mathrm{~cm}^{-1}$ may be attributed to C-OR stretching. ${ }^{38}$ The band at $1020 \mathrm{~cm}^{-1}$ corresponds to $\mathrm{C}-\mathrm{O}-\mathrm{C}$ pyranose ring vibration and the one at $880 \mathrm{~cm}^{-1}$ to $\mathrm{C}$-glucosidic $\mathrm{C}-\mathrm{H}$ deformation with a ring vibration contribution from $\mathrm{O}-\mathrm{H}$ bending. ${ }^{36}$ Based on these results, there was evidence of functional groups of cellulose, hemicellulose, and lignin, constituents of insoluble dietary fiber, which is present in high concentration in the banana peel flour.

\section{Total phenolic compounds and antioxidant activity}

The total phenolic content in the ripe banana peel flour was $183.85 \pm 5.29 \mathrm{mg}$ GAE $100 \mathrm{~g}^{-1}$ dry matter, indicating that the ripe "Prata" banana peel is a by-product with significant contents of these compounds. This result was higher than that found by Castelo-Branco et al..$^{24}$ for the peel flour (40.3 mg GAE $100 \mathrm{~g}^{-1}$ sample) and pulp flour (32.9 mg GAE $100 \mathrm{~g}^{-1}$ sample) of unripe bananas (Musa balbisiana) at stage 1 of ripening.

However, other researchers have obtained better results in comparison to the ones found in this study: in Cavendish banana peel flour, at different ripening stages (590 -2900 mg GAE $\left.100 \mathrm{~g}^{-1}\right)^{26,39}$ and unripe plantain peel flour (771 $\mathrm{mg}$ GAE $\left.100 \mathrm{~g}^{-1}\right){ }^{29}$

Therefore, the different results of total phenolic compounds found are influenced by fruit variety, cultivation conditions,

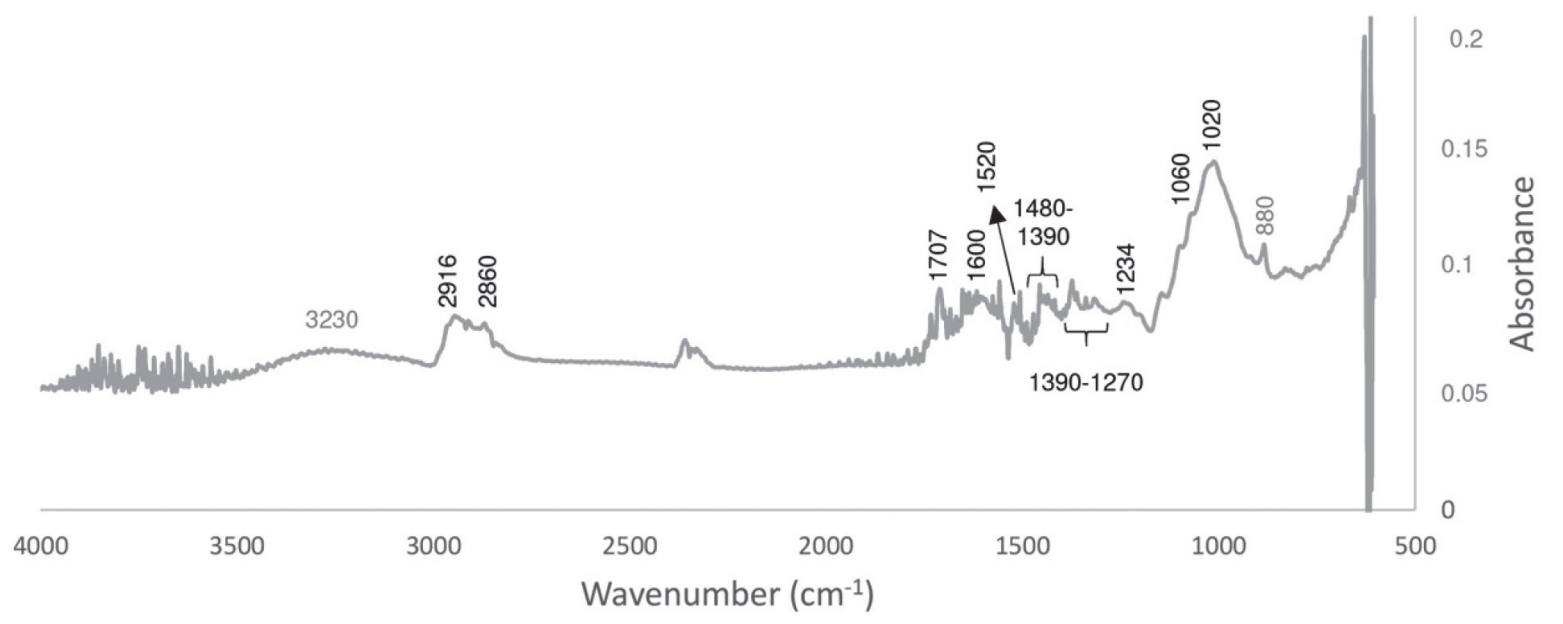

Figure 1. FTIR spectrum of ripe banana peel flour 
maturity, pre-treatment such as drying with heat, freeze drying, or blanching, and extraction conditions of compounds (solvent type, temperature, time, and extraction process). In addition, the presence of interferers such as chlorophyll, lipids, and terpenes, as well as the choice of the phenolic standard also affect the determination of these substances. ${ }^{7,40}$

Due to the various plant compounds with different polarities and biological activities, it is necessary to adopt more than one method of determination of antioxidants, which differ as to the mechanisms of action, and each has advantages and limitations. ${ }^{4}$ In this study, three methods were used to determine antioxidant activity. The results of the antioxidant activity in banana peel flour were $13.14 \pm 1.22 \mu \mathrm{mol} \mathrm{L^{-1 }}$ Trolox $\mathrm{g}^{-1}$ by ABTS, $28.92 \pm 0.78 \mu \mathrm{mol} \mathrm{L}^{-1}$ Trolox $\mathrm{g}^{-1}$ by DPPH, and $38.01 \pm 1.52 \mu \mathrm{mol} \mathrm{L}^{-1}$ ferrous sulfate $\mathrm{g}^{-1}$ by FRAP, in dry weight. These data may indicate that the compounds extracted from the flour, probably, have radicals and action sites with affinity for iron reduction reaction, acting more efficiently on the FRAP radical and also with strongly reducing molecules, capable of reacting with the DPPH free radicals.

Considering different cultivars, parts, and ripening stages of the banana, it was found that the results of the antioxidant activity described in the literature are varied. The Cavendish banana peel flour, in ripening stage 5, had $242.2 \mu \mathrm{mol} \mathrm{L}^{-1}$ Trolox $\mathrm{g}^{-1}$ by ABTS and $14.0 \mu \mathrm{M}$ Trolox $\mathrm{g}^{-1}$ by FRAP. ${ }^{39}$ The freeze-dried "Prata" banana peel, in ripening stage 6 , had antioxidant activity of $380.4 \mu \mathrm{mol} \mathrm{L}^{-1}$ Trolox g ${ }^{-1}$ sample by DPPH. ${ }^{41}$ Thus, the antioxidant activity is also influenced by cultivar, ripening stage, flour production method, as well as the conditions of extraction of compounds.
A positive correlation between the phenolic content and the antioxidant activities was found, with strong intensity $(r>0.7)$ between total content of phenolic compounds and total antioxidant activity for the methods ABTS $(r=0.914)$, FRAP $(r=0.877)$, and DPPH $(r=0.912)$, between FRAP and ABTS $(r=0.997)$, FRAP and DPPH $(r=0.997)$, and ABTS and DPPH $(r=1.000)$. These data corroborate those of other studies on banana pee ${ }^{4,41,42}$ and indicate that phenolics are the main antioxidant compounds in ripe banana peel.

However, it is important to note that there are other substances present in foods that also contribute to the ability to scavenge free radicals, such as ascorbic acid, tocopherols, phytosterols, and vegetable fibers. ${ }^{42}$ Based on these results, the flour produced can be used as a natural low-cost source of antioxidants in various foods.

\section{PS-MS fingerprints}

The paper spray-mass spectrometry (PS-MS) is a fast method to obtain fingerprints in wide ranges of masses. The extract of the banana peel flour was analyzed by PS-MS in positive and negative ionization modes, and their chemical profiles are illustrated in Figure 2. The ions and their fragments obtained in this analysis were identified based on the data described in the literature.

\section{$P S(+)-M S$ fingerprints}

The possible compounds identified in ripe banana peel flour with the positive ionization mode are shown in Table 2, most of which are within the flavonoids group. Of these, three can be proposed as glycosidic conjugates deriving from flavones: luteolin $(\mathrm{m} / \mathrm{z}, 595)$, apigenin $(\mathrm{m} / \mathrm{z}, 727)$, and chrysoeriol $(\mathrm{m} / \mathrm{z}, 797)$, as identified by
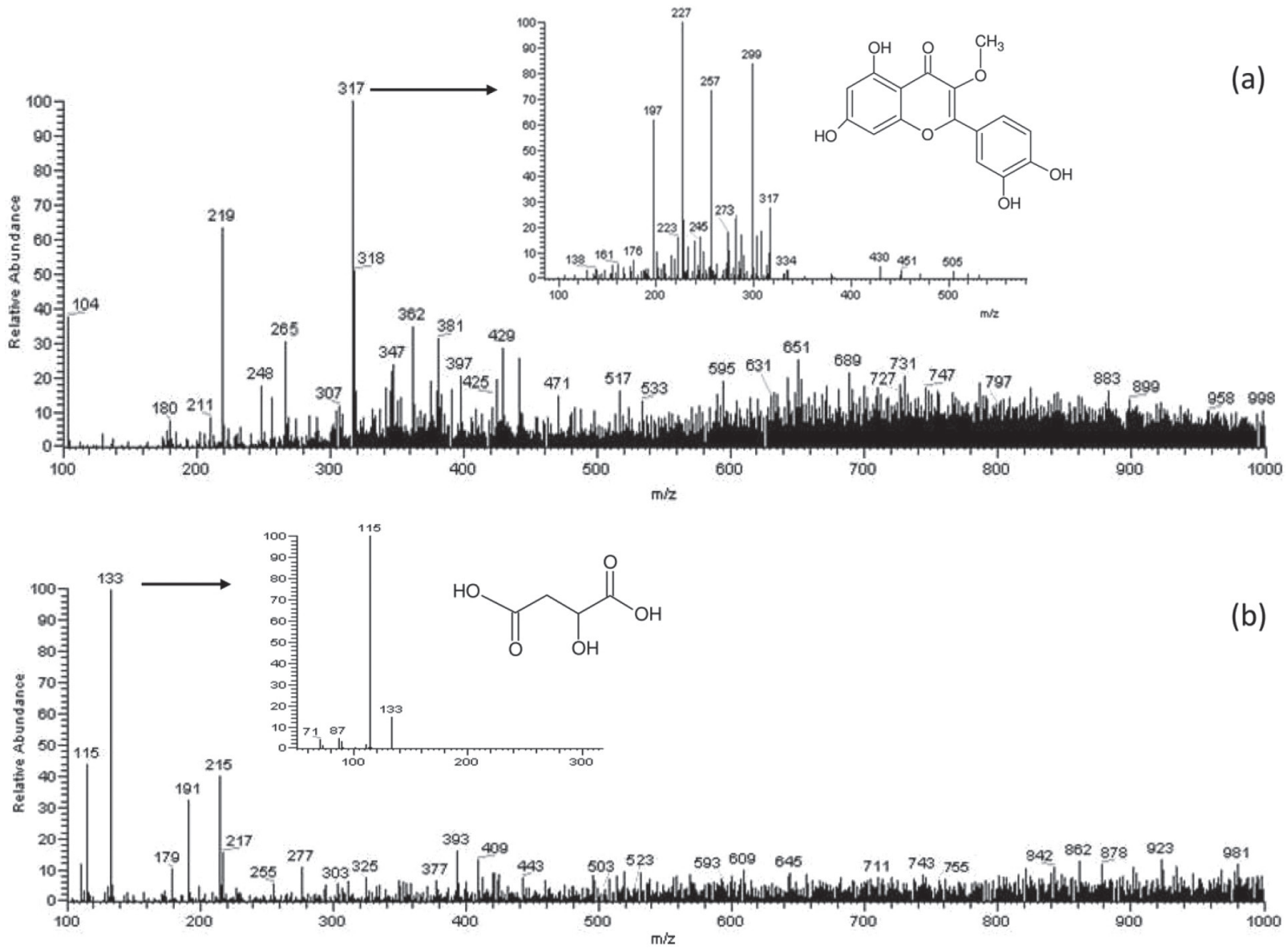

Figure 2. Representation of (a) PS(+)-MS and MS/MS spectra of the 3-O-methylquercetin (m/z, 317); (b) PS(-)-MS and MS/MS spectra of the malic acid (m/z 133) of ripe banana peel flour 
Table 2. Compounds identified in ripe banana peel flour by PS(+)-MS

\begin{tabular}{|c|c|c|c|}
\hline Tentative identification & $m / z$ & MS/MS & Reference \\
\hline \multicolumn{4}{|l|}{ Quinone } \\
\hline Spinochrome A & 265 & $191,207,219,235$ & 44 \\
\hline \multicolumn{4}{|l|}{ Flavonoids } \\
\hline 3-O-methylquercetin & 317 & 245,273 & 11,45 \\
\hline$O, \mathrm{C}$-rhamnosyl-glucosyl-luteolin & 595 & $379,409,449,451,463,469,475,577$ & 43 \\
\hline 7-O-Methyl-delphinidin-3-O-(2" galloyl)-galactoside I & 631 & 233,317 & 44 \\
\hline 6-C-hexosyl-C-pentosyl-apigenin $O$-hexoside & 727 & 709 & 43 \\
\hline Tetra-O-galloyl-scyllo-quercitol & 731 & 301 & 44 \\
\hline Chrysoeriol di- $O, O$-malonylhexoside & 797 & 711 & 43 \\
\hline \multicolumn{4}{|l|}{ Phytosterols } \\
\hline Sitosterol & 397 & 175 & 46 \\
\hline \multicolumn{4}{|l|}{ Terpenoid } \\
\hline Dihydroisovaltrate & 425 & 281,365 & 44 \\
\hline \multicolumn{4}{|l|}{ Sugars } \\
\hline Sucrose & 381 & 201,219 & 13 \\
\hline Morroniside & 429 & 267 & 12 \\
\hline
\end{tabular}

Cavaliere $e t a l .{ }^{43}$ in stem and leaves of Triticum durum using highperformance liquid chromatography (HPLC) with electrospray ionization tandem mass spectrometry (ESI-MS/MS). According to these authors, flavonoids are usually conjugated as a form of protection in plants.

The ion with $\mathrm{m} / \mathrm{z}, 317$ was proposed as being 3-O-methylquercetin based on its fragmented ions, compared to the study of Gobbo-Neto and Lopes ${ }^{45}$ with Brazilian arnica (Lychnophora ericoides) leaves using HPLC-DAD-MS and-MS/MS. The fragmentation spectrum of this ion and its chemical structure are shown in Figure 2a.

The identities of peaks represented by $\mathrm{m} / \mathrm{z}, 265$ and 425 was tentatively attributed to spinochrome A (6-acetyl-4,5,7,8-tetrahydroxynaphthalene-1,2-dione) and dihydroisovaltrate, respectively. These compounds were identified in extracts of Rhus coriaria fruits by using high-performance liquid chromatography-diode array detector-hyphenated with tandem mass spectrometry ${ }^{44}$ and are described for the first time in ripe banana peel flour.

\section{$P S(-)-M S$ fingerprints}

Table 3 presents the compounds of ripe banana peel flour identified using PS-MS in negative ionization mode, divided into organic acids, phenolic acids, phenylpropane glycerides, flavonoids, and sugars.

The ion with $m / z, 133$ was proposed as malic acid $[\mathrm{M}-\mathrm{H}]^{-}$based on its transition MS/MS $133 \rightarrow 115$ (loss of a water molecule), which was also observed by Silva et al. ${ }^{13}$ Malic acid is the major organic acid in the banana fruit ${ }^{52}$ and this was also verified in the peel flour (Figure 2b). The fragmentation spectrum of this ion and its chemical structure are shown in Figure $2 \mathrm{~b}$.

Citric acid, added in solution over the banana peels to reduce

Table 3. Compounds identified in ripe banana peel flour by PS(-)-MS

\begin{tabular}{|c|c|c|c|}
\hline Tentative identification & $\mathrm{m} / \mathrm{z}$ & MS/MS & Reference \\
\hline \multicolumn{4}{|l|}{ Organic acid } \\
\hline Malic acid & 133 & 115 & $13,44,48$ \\
\hline Citric acid & 191 & 111,173 & $13,28,46$ \\
\hline \multicolumn{4}{|l|}{ Phenolic acid } \\
\hline Caffeic acid & 179 & 135 & 49 \\
\hline Caffeic acid derivative & 377 & 341,179 & 50 \\
\hline$p$-Coumaric acid hexoside & 325 & 145 & $13,28,50$ \\
\hline 3,5-di- $O$-caffeoylquinic acid methyl ester & 535 & 373,445 & 11 \\
\hline \multicolumn{4}{|l|}{ Phenylpropane glycerides } \\
\hline 1-O-dihydrocaffeoylglycerol & 255 & 163 & 11,49 \\
\hline \multicolumn{4}{|l|}{ Flavonoids } \\
\hline Taxifolin (dihydroquercetin) & 303 & $217,259,285$ & 49 \\
\hline 4'- Methoxyluteolin-8-C-(6"acetyl)- $\beta$ - $D$-glucopyranoside & 503 & 341 & 51 \\
\hline Unknown diglucosyl flavonoid & 523 & 361 & 51 \\
\hline Kaempferol-3-O-rutinoside & 593 & 255,285 & $10,39,46,52$ \\
\hline Rutin (quercetin 3-rutinoside) & 609 & $255,271,300,301,463$ & $10,39,46,50,52$ \\
\hline Isorhamnetin-3-O-rutinoside & 623 & 315,477 & $10,39,52$ \\
\hline Quercetin-3/7-rutinoside-3/7-rhamnoside & 755 & 609 & 39 \\
\hline \multicolumn{4}{|l|}{ 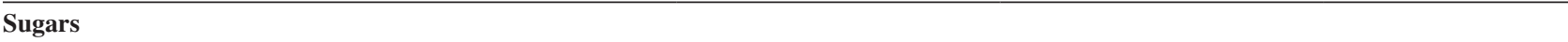 } \\
\hline Hexose & 215 & $71,89,179$ & 12,13 \\
\hline
\end{tabular}


enzymatic browning, was recognized by the ion with $\mathrm{m} / \mathrm{z}, 191$ and its fragmented ion with $\mathrm{m} / \mathrm{z} 111\left[\mathrm{M}-\mathrm{H}_{2} \mathrm{O}-\mathrm{COOH}-\mathrm{OH}\right]^{-} .^{13}$

The signals with $\mathrm{m} / \mathrm{z}, 179$ and 377 were proposed as caffeic acid and its derivative, respectively. The fragment ion of derivative at $\mathrm{m} / \mathrm{z}$ 179 could correspond to caffeic acid. These phenolic compounds are present in banana peels and have antioxidant and antimicrobial properties. $^{7}$

Of the phenylpropane glyceride class, the compound 1 - $O$-dihydrocaffeoylglycerol $(\mathrm{m} / \mathrm{z}, 255)$ was also identified in sorghum grains. ${ }^{11,49}$

The group of flavonoids was the one with largest number of substances tentatively identified. Ions with $\mathrm{m} / \mathrm{z}, 303,609$, and 755 can be considered as quercetin-based flavonols, due to their fragmented ions, compared with data from the literature. Rebello et al. ${ }^{39}$ found in the Cavendish banana peel flour in stage 5 of ripening that quercetinbased glycosides were the most important flavonols. Other flavonoidconjugated glycosides were also tentatively identified in the sample as the ions with $\mathrm{m} / \mathrm{z}, 503,523,593$, and 623 since their fragmentation pattern obtained in this study correspond to those found in the literature.

The signal with $\mathrm{m} / z 215$ can be considered as hexose. The banana peel flour has a high content of carbohydrates that can be identified by the paper spray technique. Silva et al., ${ }^{13}$ using the same method, also tentatively identified sugars in cagaitas (Eugenia dysenterica) with the same transition MS/MS.

According to $\mathrm{Vu}$ et al., ${ }^{7}$ the banana peel contains over 40 phenolic compounds that have already been identified, including flavonoids, catecholamines, and hydroxycinnamic acids. Tsamo et al. ${ }^{10}$ and Rebello et al. ${ }^{39}$ detected in significant quantities conjugates with hexoses, flavonoid glycosides, and quercetin-based structures, and rutin and its conjugates were the main flavonols from banana peel. Tsamo et al..$^{10}$ found that flavonol glycosides were dominant in the plantain peels while ferulic acid was found in greater quantity in the plantain pulp. However, ferulic acid and catecholamines were not identified in the ripe banana peel flour of the present study.

These variations in the type of compound identified depend on several factors such as fruit variety, ripening, and cultivation conditions, and pre-treatment and extraction methods.

\section{CONCLUSIONS}

Banana peel is a waste of easy availability and low cost from which one can obtain a flour that contains bioactive compounds, antioxidant property, high levels of carbohydrates and dietary fiber, and may be an alternative source for the development of new products. The antioxidant activity had strong positive correlation with the content of total phenolic compounds. By the PS-MS technique, in a quick and simple way, eleven compounds were tentatively identified by the positive mode and fifteen by the negative mode, such as organic acids, phenolics acids, flavonoids, sugars, quinone, and terpenoids in the ripe banana peel flour. It is noted that this study was the first to employ the ionization technique by paper spray to evaluate the chemical profile of ripe banana peel flour.

\section{SUPPLEMENTARY MATERIAL}

A table containing the compounds identified in ripe banana peel flour by PS-MS, with their CAS numbers and chemical structures, can be freely accessed at http://quimicanova.sbq.org.br in PDF format.

\section{ACKNOWLEDGMENTS}

The authors would like to thank Minas Gerais Research Support Foundation (FAPEMIG), Coordination for the Improvement of Higher
Education Personnel (CAPES), and National Council for Scientific and Technological Development (CNPq) for the financial support.

\section{REFERENCES}

1. Food and Agriculture Organization of the United Nations (FAO); Banana facts and figures, available at http://www.fao.org/economic/est/ est-commodities/bananas/bananafacts/en/\#.XRobD-hKjIV, accessed in April 2020.

2. Instituto Brasileiro de Geografia e Estatística (IBGE); Produção brasileira de banana safra 2019, available at http://sidra.ibge.gov.br/ tabela/1618\#resultado, accessed in April 2020.

3. Kowalska, H.; Czajkowska, K.; Cichowska, J.; Lenart, A.; Trends Food Sci. Technol. 2017, 67, 150.

4. Vu, H. T.; Scarlett, C. J.; Vuong, Q. V.; Journal of Food Processing and Perservation 2017, 41, e13148.

5. Pereira, A.; Maraschin, M.; J. Ethnopharmacol. 2015, 160, 149.

6. Emaga, T. H.; Andrianaivo, R. H.; Wathelet, B.; Tchango, J. T.; Paquot, M.; Food Chem. 2007, 103, 590.

7. Vu, H. T.; Scarlett, C. J.; Vuong, Q. V.; J. Funct. Foods 2018, 40, 238.

8. Anjum, S.; Sundaram, S.; Rai, G. K.; Int. J. Pharm. Pharm. Sci. 2014, $6,81$.

9. Kamel, N. A.; Abd-El-messieh, S. L.; Saleh, N. M.; Mater. Sci. Eng. C 2017, 72, 543; Jung, E. P.; Ribeiro, L. O.; Kunigami, C. N.; Figueiredo, E. S.; Nascimento, F. S.; Rev. Virtual Quim. 2019, 11, 1712.

10. Tsamo, C. V. P.; Herent, M. F.; Tomekpe, K.; Emaga, T. H.; QuetinLeclercq, J.; Rogez, H.; Larondelle, Y.; Andre, C.; Food Chem. 2015, 167, 197.

11. Campelo, F. A.; Henriques, G. S.; Simeone, M. L. F.; Queiroz, V. A. V.; Silva, M. R.; Augusti, R.; Melo, J. O. F.; Lacerda, I. C. A.; Araújo, R. L. B.; J. Braz. Chem. Soc. 2020, 31, 788.

12. Guo, Y.; Gu, Z.; Liu, X.; Liu, J.; Ma, M.; Chena, B.; Wang, L.; Phytochem. Anal. 2017, 28, 344.

13. Silva, M. R.; Freitas, L. G.; Souza, A. G.; Araújo, R. L. B.; Lacerda, I. C. A.; Pereira, H. V.; Augusti, R.; Melo, J. O. F.; J. Braz. Chem. Soc. 2019, 30, 1034

14. Wang, H.; Liu, J.; Cooks, R. G.; Ouyang, Z.; Angew. Chem., Int. Ed. Engl. 2010, 49, 877.

15. Leão, D. P.; França, A. S.; Oliveira, L. S.; Bastos, R.; Coimbra, M. A.; Food Chem. 2017, 225, 146.

16. Alkarkhi, A. F. M.; bin Ramli, S.; Yong, Y. S.; Easa, A. M.; Food Chem. 2011, 129, 312

17. Wang, L.; Xu, H.; Yuan, F.; Fan, R.; Gao, Y.; Food Chem. 2015, 185, 90.

18. Association of Official Analytical Chemistry (AOAC); Official Methods of Analysis, 19 $9^{\text {th }}$ ed., AOAC: Gaithersburg, 2012.

19. Instituto Adolfo Lutz (IAL); Métodos físico-químicos para análise de alimentos, Instituto Adolfo Lutz: São Paulo, 2008.

20. Brasil; Ministério da Agricultura Pecuária e Abastecimento, Secretaria de Defesa Agropecuária, Coordenação-Geral de Laboratórios Agropecuários, Laboratório Nacional Agropecuário, Laboratório de Análises para Classificação Vegetal, Determinação de amido em farinha de mandioca, produtos amiláceos e outros, Lanagro/RS: Porto Alegre, 2014.

21. Asp, N. G.; Johansson, C. G.; Hallmer, H.; Siljeström, M.; J. Agric. Food Chem. 1983, 31, 476

22. Rufino, M. S. M.; Alves, R. E.; de Brito, E. S.; Pérez-Jiménez, J.; SauraCalixto, F.; Mancini-Filho, J.; Food Chem. 2010, 121, 996.

23. Sahan, Y.; Cansev, A.; Gulen, H.; Food Sci. Biotechnol. 2013, 22, 613.

24. Castelo-Branco, V. N.; Guimarães, J. N.; Souza, L.; Guedes, M. R.; Silva, P. M.; Ferrão, L. L.; Miyahira, R. F.; Guimarães, R. R.; Freitas, S. M. L.; Reis, M. C.; Zago, L.; Braz. J. Food Technol. 2017, 20, 1.

25. Vu, H. T.; Scarlett, C. J.; Vuong, Q. V.; Drying Technol. 2017, 35, 1141. 26. Khawas, P.; Deka, S. C.; Int. J. Food Prop. 2016, 19, 2832. 
27. Torres-Oblitas, K.; Sancho, A. M.; Gozzi, M. S.; Ciênc. Tecnol. Aliment 2018, 28, 22.

28. Zhang, L. L.; Zhu, M. T.; Shi, T.; Guo, C.; Huang, Y. S.; Chen, Y.; Xie, M. Y.; Food Funct. 2017, 8, 341.

29. Agama-Acevedo, E.; Sañudo-Barajas, J. A.; Vélez De La Rocha, R.; González-Aguilar, G. A.; Bello-Peréz, L. A.; CyTA - J. Food 2016, 14, 117.

30. Resende, L. M.; França, A. S.; Oliveira, L. S.; Food Chem. 2019, 270, 53.

31. Joshi, A. U.; Liu, C.; Sathe, S. K.; LWT -- Food Sci. Technol. 2015, 60, 325.

32. Zhang, W.; Zeng, G.; Pan, Y.; Chen, W.; Huang, W.; Chen, H.; Li, Y.; Carbohydr. Polym. 2017, 172, 102.

33. Agência Nacional de Vigilância Sanitária (ANVISA); RDC no 263, de 22 de setembro de 2005. Diário Oficial da União, $\mathrm{n}^{\circ} 184$, de 23 de setembro de 2005, Brasília, available at http://portal.anvisa.gov.br/ legislacao\#/visualizar/27619, accessed in April 2020.

34. Angelis-Pereira, M. C.; Barcelos, M. F. P.; Pereira, R. C.; Pereira, J. A. R.; Sousa, R. V.; Nutr. Food Sci. 2016, 46, 504.

35. Dahl, W. J.; Stewart, M. L.; J. Acad. Nutr. Diet. 2015, 115, 1861.

36. Pelissari, F. M.; Sobral, P. J. A.; Menegalli, F. C.; Cellulose 2014, 21, 417.

37. Oliveira, T. Í. S.; Rosa, M. F.; Cavalcante, F. L.; Pereira, P. H. F.; Moates, G. K.; Wellner, N.; Mazzetto, S. E.; Waldron, K. W.; Azeredo, H. M.C.; Food Chem. 2016, 198, 113.

38. El-Din, G. A.; Amer, A. A.; Malsh, G.; Hussein, M.; Alexandria Eng. J. 2018, 57, 2061.

39. Rebello, L. P. G.; Ramos, A. M.; Pertuzatti, P. B.; Barcia, M. T.; CastilloMuñoz, N.; Hermosín-Gutiérrez, I.; Food Res. Int. 2014, 55, 397.
40. Aboul-Enein, A. M.; Salama, Z. A.; Gaafar, A. A.; Aly, H. F.; AbouElella, F.; Ahmed, H. A.; J. Chem. Pharm. Res. 2016, 8, 46.

41. Pereira, G. A.; Molina, G.; Arruda, H. S.; Pastore, G. M.; J. Food Process Eng. 2017, 40, 1.

42. González-Montelongo, R.; Lobo, M. G.; González, M.; Sep. Purif. Technol. 2010, 71, 347.

43. Cavaliere, C.; Foglia, P.; Pastorini, E.; Samperi, R.; Lagana, A.; Rapid Commun. Mass Spectrom. 2005, 19, 3143.

44. Abu-Reidah, I. M.; Ali-Shtayeh, M. S.; Jamous, R. M.; Arráez-Román, D.; Segura-Carretero, A.; Food Chem. 2015, 166, 179.

45. Gobbo-Neto, L.; Lopes, N. P.; J. Agric. Food Chem. 2008, 56, 1193.

46. Wang, J.; Jia, Z.; Zhang, Z.; Wang, Y.; Liu, X.; Wang, L.; Lin, R.; Molecules 2017, 22, 47.

47. Oliveira, D. S.; Lima, L. S.; Antonio, A. S.; Wiedemann, L. S. M.; VeigaJunior, V. F.; Quim. Nova 2020, 43, 72.

48. Kang, J.; Price, W.; Ashton, J.; Tapsell, L.; Johnson, S.; Food Chem. 2016, 211, 215.

49. Bystrom, L. M.; Lewis, B. A.; Brown, D. L.; Rodriguez, E.; Obendorf, R. L.; Food Chem. 2008, 111, 1017.

50. Simirgiotis, M. J.; Schmeda-Hirschmann, G.; Bórquez, J.; Kennelly, E. J.; Molecules 2013, 18, 1672.

51. Brito, A.; Ramirez, J. E.; Areche, C.; Sepúlveda, B.; Simirgiotis, M. J.; Molecules 2014, 19, 17400.

52. Thakur, R.; Pristijono, P.; Bowyer, M.; Singh, S. P.; Scarlett, C. J.; Stathopoulos, C. E.; Vuong, Q. V.; LWT -- Food Sci. Technol. 2019, 100, 341 . 